\title{
Outcomes after transcatheter valve-in-valve implantation using a balloon-expandable Edwards Sapien valve in patients with degenerated Freestyle aortic bioprosthesis
}

\author{
Christof Burgdorf, Andrijana Vukadinovikj Momchilovska, Bjoern Andrew Remppis \\ Klinik für Kardiologie, Herz- und Gefäßzentrum Bad Bevensen, Bad Bevensen, Germany \\ Correspondence to: Christof Burgdorf. Klinik für Kardiologie, Herz- und Gefäßzentrum Bad Bevensen, Römstedter Straße 25, 29549 Bad Bevensen, \\ Germany. Email: c.burgdorf@hgz-bb.de.
}

\begin{abstract}
Background: Transcatheter aortic valve-in-valve implantation (ViV TAVI) in degenerated Medtronic Freestyle aortic bioprosthesis (FSB) has been reported as being technically challenging. This study sought to evaluate procedural data and outcomes after ViV TAVI using a balloon-expandable Edwards valve in patients with failed FSB.
\end{abstract}

Methods: Between August 2014 and December 2020, twenty-seven consecutive patients underwent ViV TAVI for symptomatic FSB failure at our institution using a Sapien XT (n=1) and Sapien $3(n=26)$ valve, respectively. Endpoints were defined according to the Valve Academic Research Consortium-2 (VARC-2) criteria and were retrospectively analyzed.

Results: Mean patient age was $75.7 \pm 8.2$ years (female $n=5$, male $n=22$ ); Society of Thoracic Surgeons Predicted Risk of Mortality score was $7.3 \% \pm 6.2 \%$. ViV implantation with correct positioning of the Edwards Sapien valve within the FSB was successful in all cases. Intraprocedural transesophageal echocardiography revealed none/trace paravalvular regurgitation in twenty-five patients (92.6\%), mild paravalvular regurgitation was present in two patients $(7.4 \%)$. Neither of the patients had a mean gradient $\geq 20.0 \mathrm{mmHg}$ excluding significant patient-prosthesis mismatch. Three early deaths ( $\leq$ thirty days) occurred resulting in a device success rate of $88.8 \%$. One-year and three-year survival rates for patients alive beyond day thirty after ViV TAVI were $95.8 \%$ and $70.0 \%$, respectively.

Conclusions: ViV TAVI with Edwards Sapien valves lead to acceptable functional results in high-risk patients with degenerated FSB but early complications must be considered particularly during hospital stay.

Keywords: Valve-in-valve; transcatheter; Freestyle aortic bioprosthesis (FSB); Edwards Sapien

Submitted Mar 24, 2021. Accepted for publication Jul 29, 2021.

doi: 10.21037/acs-2021-tviv-fs-43

View this article at: https://dx.doi.org/10.21037/acs-2021-tviv-fs-43

\section{Introduction}

Transcatheter valve-in-valve implantation (ViV TAVI) for degenerated aortic bioprosthesis is expected to continue to grow in numbers worldwide (1). The majority of $\mathrm{ViV}$ procedures have so far been performed in failed stented bioprostheses with similar operative and intermediateterm mortality compared to redo surgical aortic valve replacement (2-5). Technically, ViV TAVI in stentless bioprostheses has been reported as being more demanding as compared to reintervention after implantation of a stented bioprosthesis due to missing fluoroscopic markers or increased calcification for identification of the annulus, absence of a stented frame for reliable anchoring of the transcatheter valve, and the often small distance to coronary ostia $(6,7)$.

After Food and Drug Administration approval and commercial introduction in 1997, the Medtronic Freestyle aortic bioprosthesis (FSB) is one of the most implanted stentless aortic bioprosthesis worldwide (8-10). Surgical redo, particularly after full-root aortic valve replacement, 
has been reported as being challenging and may not be suitable for high-risk patients and therefore, ViV TAVI has been suggested as an alternative, less invasive therapeutic option in this setting (11). Recent data from a cohort of fifty-six patients with failing FSB treated with either Medtronic CoreValve, Evolut R, or Evolut Pro indicated a device success of $82 \%$ after ViV TAVI and a likewise threeyear survival rate of $82 \%$ (12). Since outcomes in the latter study are specific to self-expanding transcatheter valves, it was speculated whether balloon-expandable valves may provide different results (12).

Therefore, the present study was undertaken to evaluate procedural data and outcomes after ViV TAVI using a balloon-expandable Edwards valve in patients with failed FSB.

\section{Methods}

The present retrospective observational study complies with the guidelines for human studies and was conducted ethically in accordance with the World Medical Association Declaration of Helsinki. The study protocol was approved by an institutional review board.

\section{Patients}

Between August 2014 and December 2020, out of a total of 1,198 consecutive TAVI procedures, twenty-seven patients underwent $\mathrm{ViV}$ TAVI for symptomatic FSB failure at our institution using a balloon-expandable Edwards Sapien valve. Primary implantation of the FSB was performed as full root replacement in twenty-six patients, while one patient had a subcoronary valve replacement. The heart team, consisting of an interventional cardiologist, cardiac surgeon, echocardiographer, radiologist, and cardiac anesthetist reviewed all cases and recommended ViV TAVI based on clinical presentation, comorbidities, anatomical/ morphological details of the aortic root and predicted risk of reintervention.

Clinical outcomes after ViV TAVI were analyzed according to the Valve Academic Research Consortium-2 (VARC-2) criteria at thirty-days, one-year and three-years (13).

\section{ViV TAVI}

ViV TAVI was performed according to standard techniques with transfemoral vascular access as preferred approach $(n=19)$. Due to peripheral artery disease, in eight patients, transapical access was required. For the choice of the size of the Edwards Sapien valve, aortic root dimensions (as determined by multislice computed tomography, angiography, and echocardiography) as well as the size and implantation technique of the existing FSB were considered. In detail, one patient with $21 \mathrm{~mm}$ FSB was treated with a $23 \mathrm{~mm}$ Sapien 3 valve, two patients with $23 \mathrm{~mm}$ FSB were treated with a $23 \mathrm{~mm}$ and a $26 \mathrm{~mm}$ Sapien 3 valve, respectively; three patients with $25 \mathrm{~mm} \mathrm{FSB}$ were treated with a $26 \mathrm{~mm}$ Sapien 3 valve and one patient with $25 \mathrm{~mm}$ FSB treated with a $29 \mathrm{~mm}$ Sapien 3 valve, respectively, and twenty patients with either $27 \mathrm{~mm} \mathrm{FSB}$ ( $\mathrm{n}=9$ ) or $29 \mathrm{~mm}$ FSB $(n=11)$ were treated with a $29 \mathrm{~mm}$ Sapien valve (Sapien $\mathrm{XT} n=1$, Sapien $3 \mathrm{n}=19$ ).

To define perpendicular annulus plane by fluoroscopy and to obtain the alignment of the right cusp between the left and the non-coronary cusp, root angiography was used with the pigtail catheter being placed in the right coronary sinus (14). Rapid ventricular pacing ( $\approx 180 \mathrm{bpm}$ ) plus angiography was applied for cardiac output reduction and final device alignment during deployment. All TAVI procedures were done under general anesthesia. Transesophageal echocardiography (TEE) for assessment of acute TAVI prosthesis function, intra-annular positioning, and exclusion of left ventricular wall motion abnormities was present during all procedures.

\section{Statistical analysis}

Continuous data are presented as mean \pm standard deviation; frequencies and percentages are used to describe discrete variables. Continuous data were analyzed using the MannWhitney nonparametric $U$ test. A P value of less than 0.05 was considered statistically significant. All analyses were performed using GraphPad Prism 7.0 (GraphPad Software Inc., San Diego, CA, USA).

\section{Results}

\section{Patient characteristics}

Pre-interventional clinical characteristics of the entire cohort are given in Table 1. The Society of Thoracic Surgeons Predicted Risk of Mortality score was $7.3 \% \pm 6.2 \%$, indicating a high-risk cohort. Symptomatic moderate or severe regurgitation of the FSB was unexceptionally the clinical indication for transcatheter reintervention and NTproBNP level was already markedly elevated at the time of intervention. Time from previous FSB surgery to ViV TAVI 


\begin{tabular}{|c|c|}
\hline Characteristics & Data \\
\hline Age (years) & $75.7 \pm 8.2$ \\
\hline Female:male (n) & $5: 22$ \\
\hline Body mass index $\left(\mathrm{kg} / \mathrm{m}^{2}\right)$ & $28.4 \pm 4.6$ \\
\hline NYHA classification $\geq$ III, n (\%) & $20(74.1)$ \\
\hline Mitral regurgitation $\geq \mathrm{II}, \mathrm{n}$ (\%) & $10(37.0)$ \\
\hline Tricuspid regurgitation $\geq$ II & - \\
\hline LVEF (\%) & $50.4 \pm 11.1$ \\
\hline LVEDV (mL) & $165.6 \pm 58.1$ \\
\hline Systolic PAP (mmHg) & $38.8 \pm 8.2$ \\
\hline Coronary artery disease, n (\%) & $22(81.5)$ \\
\hline Prior MI, n (\%) & 7 (25.9) \\
\hline Prior PCl, n (\%) & $6(22.2)$ \\
\hline Sinus rhythm, n (\%) & $11(40.7)$ \\
\hline AV block, n (\%) & $9(33.3)$ \\
\hline Bundle branch block, n (\%) & $12(44.4)$ \\
\hline Atrial fibrillation, n (\%) & $16(59.3)$ \\
\hline Pacemaker/ICD, n (\%) & $6(22.2)$ \\
\hline COPD, n (\%) & $9(33.3)$ \\
\hline Extracardiac arteriopathy, $\mathrm{n}(\%)$ & $11(40.7)$ \\
\hline Creatinine $(\mathrm{mg} / \mathrm{dL})$ & $1.5 \pm 0.7$ \\
\hline GFR (mL/min) & $58.6 \pm 21.5$ \\
\hline NT-proBNP (ng/L) & $6,750 \pm 8,315$ \\
\hline Previous stroke/TIA, n (\%) & $4(14.8)$ \\
\hline Previous isolated FSB surgery, $\mathrm{n}(\%)$ & $7(25.9)$ \\
\hline Previous combined procedures, $\mathrm{n}(\%)$ & $20(74.1)$ \\
\hline CABG, n (\%) & $14(70.0)$ \\
\hline Mitral valve repair, $\mathrm{n}(\%)$ & $1(5.0)$ \\
\hline Tricuspid valve repair, $\mathrm{n}(\%)$ & $1(5.0)$ \\
\hline Replacement of ascending aorta, n (\%) & $11(55.0)$ \\
\hline Left atrial appendage resection, $\mathrm{n}(\%)$ & $3(15.0)$ \\
\hline >1 previous cardiac surgery, $\mathrm{n}(\%)$ & $8(29.6)$ \\
\hline
\end{tabular}

$\mathrm{AV}$, atrioventricular; $\mathrm{CABG}$, coronary artery bypass grafting; COPD, chronic obstructive pulmonary disease; FSB, Freestyle stentless bioprosthesis; GFR, glomerular filtration rate; ICD, implantable cardioverter defibrillator; LVEF, left ventricular ejection fraction; LVEDV, left ventricular end-diastolic volume; MI, myocardial infarction; NT-proBNP, N-terminal pro-brain natriuretic peptide; NYHA, New York Heart Association; PAP, pulmonary artery pressure; $\mathrm{PCl}$, percutaneous coronary intervention; TIA, transient ischemic attack. was $11.5 \pm 3.8$ years. Twenty-six $\mathrm{ViV}$ procedures were done electively, one patient required emergent ViV TAVI because of acute decompensated refractory heart failure.

\section{Procedural ViV characteristics}

Transcatheter $\mathrm{ViV}$ implantation with correct positioning of the Edwards Sapien valve within the FSB as intended was successful in all cases (Figure 1). Immediate intraprocedural TEE revealed none/trace paravalvular regurgitation in twenty-five patients $(92.6 \%)$, mild paravalvular regurgitation was present in two patients $(7.4 \%)$.

As expected, transapical $(\mathrm{n}=8)$ intervention time was significantly longer than transfemoral $(\mathrm{n}=19)$ intervention time $(129.9 \pm 67.9$ versus $75.0 \pm 44.7 \mathrm{~mm}, \mathrm{P}<0.05)$ whereas no significant differences between both approaches were seen with respect to fluoroscopy time (transapical $12.1 \pm 8.4 \mathrm{~min}$, transfemoral $12.7 \pm 5.7 \mathrm{~min}$ ) and consumption of contrast dye (transapical $190.5 \pm 130.9 \mathrm{~mL}$, transfemoral $158.4 \pm 55.6 \mathrm{~mL}$ ). Postimplant balloon dilatation was necessary in three patients after transfemoral ViV TAVI and in one patient after transapical ViV TAVI. Concomitantly planned percutaneous coronary intervention of the left main was done in one patient with transapical ViV TAVI. One patient had a MitraClip ${ }^{\circledR}$ procedure six weeks prior to ViV TAVI at our institution.

\section{Follow-up echocardiography}

Follow-up transthoracic echocardiography during hospital stay was available from twenty-five patients after ViV TAVI, two patients died before echocardiographic re-evaluation. Of those who had postinterventional echocardiography, aortic valve regurgitation was identical to intraprocedural TEE findings. Mean and maximal transvalvular pressure gradients were $10.1 \pm 3.1$ and $18.8 \pm 6.1 \mathrm{mmHg}$, respectively. Neither of the patients had a mean gradient $\geq 20.0 \mathrm{mmHg}$ excluding significant patient-prosthesis mismatch.

\section{Outcomes}

Early outcomes are summarized in Table 2. Device success according to VARC-2 criteria was $88.8 \%$ triggered by three procedure-related deaths within the first thirty days after ViV TAVI. In detail, one patient died on the third day after intervention because of massive gastrointestinal bleeding and concurrent refractory hemorrhagic shock. In another patient with known pre-interventional severely impaired 

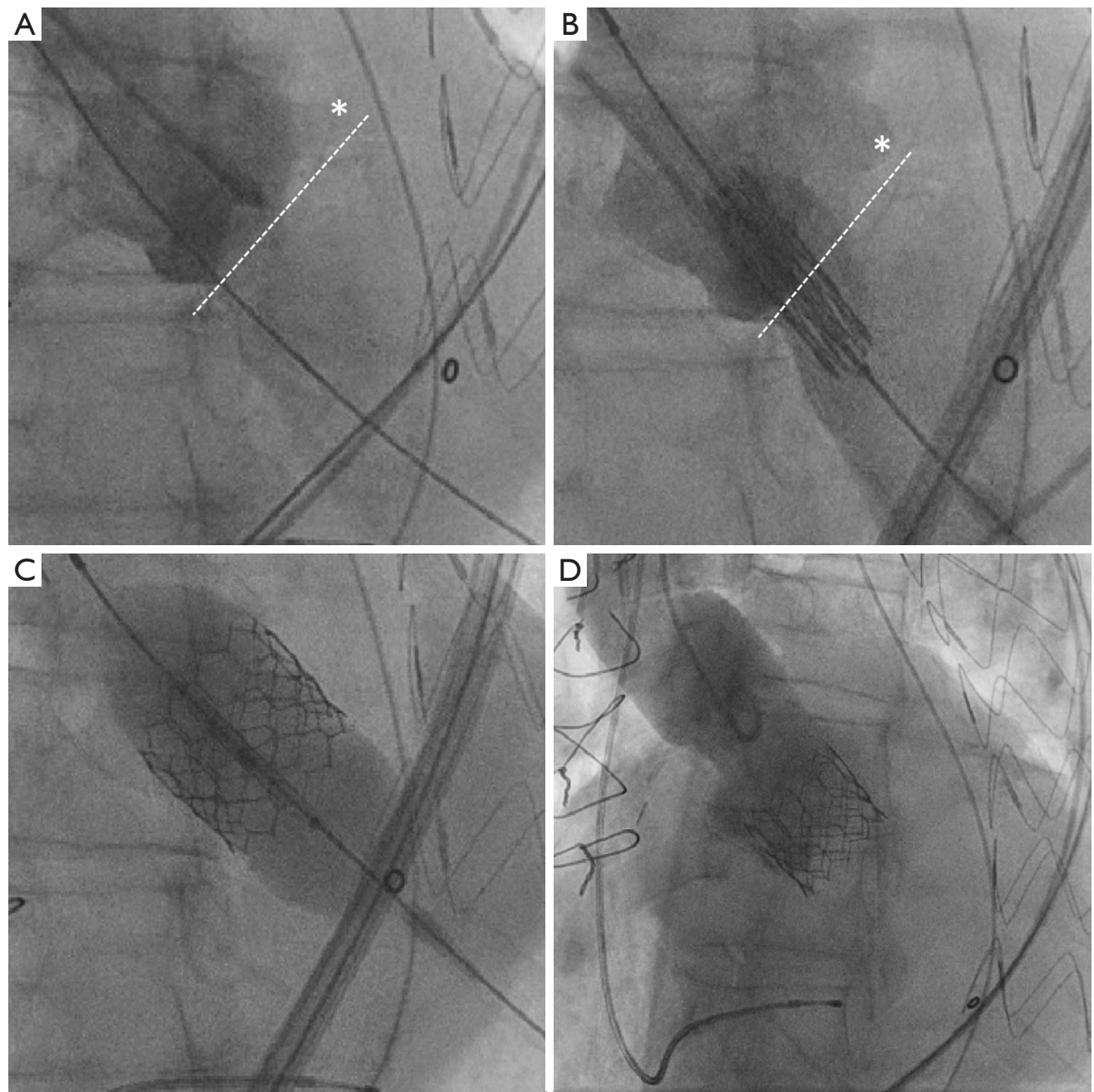

Figure 1 Exemplary transfemoral transcatheter valve-in-valve implantation (Edwards Sapien 329 mm) in a patient with degenerated 27 $\mathrm{mm}$ Medtronic Freestyle aortic bioprosthesis. (A) Determination of the line of perpendicularity $\left(^{*}\right)$, (B) positioning of the crimped valve, $(\mathrm{C})$ balloon expansion, and (D) final angiography of the aortic root.

left ventricular function, post-procedural echocardiography showed new severe mitral regurgitation. In this patient, transapical access for ViV TAVI was performed, and retrospective analysis of angiography, showed that during delivery of the Sapien valve, the sub-valvular apparatus of the mitral valve was affected by the delivery system resulting in a flail of the anterior leaflet. During subsequent surgical mitral valve replacement, the aortic root including the TAVI prosthesis as well as the ascending aorta had also been replaced for surgical reasons. Although maximum medical efforts including implantation of an intra-aortic balloon pump were done, this patient died due to refractory cardiogenic shock on the sixth day after ViV TAVI. Finally, one female patient died after surgical reconstruction of the femoral artery at the puncture site and development of retroperitoneal hematoma and hemorrhagic shock on day twelve after ViV TAVI.

Eighteen patients $(66.6 \%)$ were extubated in the operating room (length of mechanical ventilation $2.1 \pm 0.6 \mathrm{~h}$ ) and nine patients $(33.3 \%)$ were extubated on the Intensive Care Unit (length of mechanical ventilation $196.3 \pm 518.6$ h). Accordingly, given the length of mechanical ventilation, Intensive Care Unit stay was significantly longer in patients

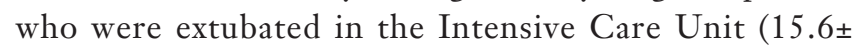
25.3 versus $5.3 \pm 6.7$ days, $\mathrm{P}<0.05$ ).

Mean follow-up for patients alive beyond day thirty after 


\begin{tabular}{|c|c|}
\hline & Data \\
\hline Procedural mortality ( $\leq 72$ h), n (\%) & $1(3.7)$ \\
\hline 30-day mortality, n (\%) & $3(11.1)$ \\
\hline Myocardial infarction & - \\
\hline Stroke/TIA, n (\%) & $1(3.7)$ \\
\hline Intracerebral bleeding & - \\
\hline Delirium, n (\%) & $2(7.4)$ \\
\hline New bundle branch and/or AV block, $\mathrm{n}(\%)$ & $4(14.8)$ \\
\hline New atrial fibrillation, $\mathrm{n}(\%)$ & $2(7.4)$ \\
\hline New permanent pacemaker, n (\%) & $2(7.4)$ \\
\hline \multicolumn{2}{|l|}{ Vascular complications } \\
\hline Major, n (\%) & $1(3.7)$ \\
\hline Minor, n (\%) & $2(7.4)$ \\
\hline \multicolumn{2}{|l|}{ Bleeding } \\
\hline Life-threatening, $\mathrm{n}(\%)$ & $4(14.8)$ \\
\hline Major, n (\%) & $8(29.6)$ \\
\hline Minor, n (\%) & $1(3.7)$ \\
\hline \multicolumn{2}{|l|}{ Acute kidney injury } \\
\hline Stage $1, \mathrm{n}(\%)$ & $2(7.4)$ \\
\hline Stage $2, \mathrm{n}(\%)$ & - \\
\hline Stage 3, n (\%) & $2(7.4)$ \\
\hline Pneumonia, n (\%) & $4(14.8)$ \\
\hline Reintubation, n (\%) & $3(11.1)$ \\
\hline Tracheotomy, n (\%) & $1(3.7)$ \\
\hline Sepsis, n (\%) & $1(3.7)$ \\
\hline Reintervention, n (\%) & $1(3.7)$ \\
\hline Aortic valve endocarditis, $\mathrm{n}(\%)$ & $1(3.7)$ \\
\hline
\end{tabular}

ViV TAVI was $2.3 \pm 1.7$ years (range, 53 days -5.3 years). One-year and three-year survival rates were $95.8 \%$ and $70.0 \%$, respectively (Figure 2).

\section{Discussion}

The present study is the first to give procedural data and outcomes of a homogenous cohort of high-risk patients with degenerated FSB treated with a balloon-expandable
Edwards Sapien valve. The main findings are as follows: (I) Transcatheter treatment of degenerated FSB with an Edwards Sapien valve lead to acceptable acute procedural results. (II) Early complications after ViV treatment must be considered particularly during post-procedural hospital stay.

So far, most data of ViV TAVI were derived from a heterogeneous mix of degenerated stented and stentless bioprostheses subsumed within cohorts or registries of patients with ViV TAVI, respectively, although it is well known that the underling morphological and functional alterations completely differ between stented and stentless bioprostheses $(3,15)$. Furthermore, in previous $\mathrm{ViV}$ studies, results of self-expandable transcatheter valves from different manufacturers were mixed with results from different generations of balloon-expandable Edwards valves $(2,3,16)$.

Using first-generation Medtronic CoreValve and subsequently Evolut R and Evolut Pro, respectively, Wai Sang and colleagues are the only ones so far who described their $\mathrm{ViV}$ results in a homogenous cohort of fifty-six consecutive patients with failed FSB (12). Procedural success was achieved in forty-six patients $(82 \%)$ with the majority of device failures due to the requirement of more than one transcatheter valve (six patients). Numerically, device success of $88.8 \%$ in our study was somewhat higher but did not differ substantially to the result of the latter study, however, device failure in our study was triggered causally by three postprocedural deaths. Intraprocedural complications such as prosthesis migration with requirement of a second valve as described by Wai Sang and colleagues (12) did not occur in any of our patients and echocardiography demonstrated excellent valve function in all cases without evidence of patient-prosthesis mismatch. Furthermore, coronary obstruction, which has also been described in a previous $\mathrm{ViV}$ study with sixty-six patients with failed stentless bioprosthesis (including fifty-six patients with FSB) (7) did not happen in our series.

Hemodynamic data suggest that self-expandable supraannular transcatheter valves might be more favorable than balloon-expandable intra-annular valves for $\mathrm{ViV}$ indication because of better postprocedural performance in terms of residual transvalvular gradients, larger effective orifice areas, and lower rates of prosthesis-patient mismatch (17). Again, however, this assumption was derived from a mix of patients with both degenerated stented and stentless aortic bioprostheses. Residual mean transvalvular pressure gradient of $10.1 \pm 3.1 \mathrm{mmHg}$ in the present study using balloon-expandable Edwards valves was very similar to 


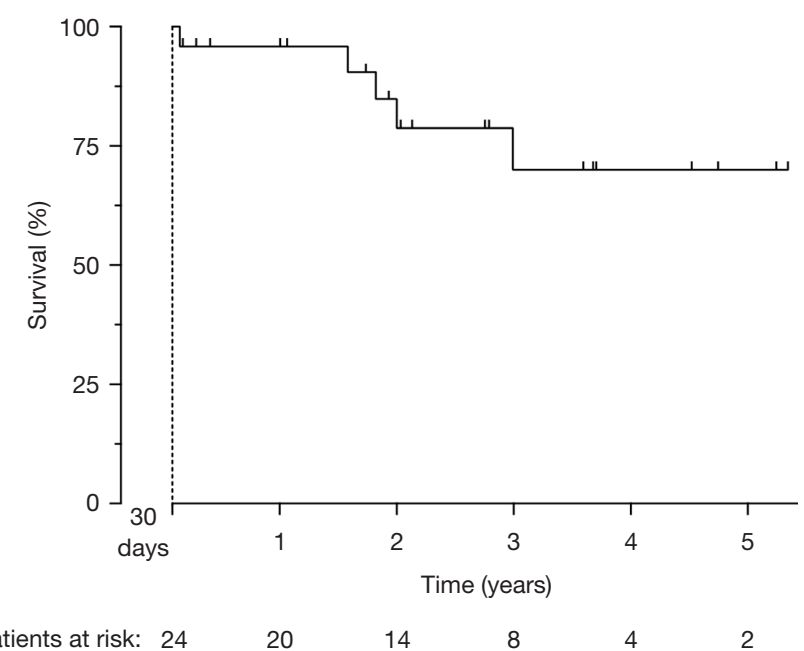

Figure 2 Kaplan-Meier survival rates for patients alive beyond day 30 after transcatheter valve-in-valve implantation.

the residual pressure gradient after ViV TAVI with selfexpandable Medtronic CoreValve valves as described previously by Wai Sang and colleagues $(11 \pm 8 \mathrm{mmHg})$ and Huczek and colleagues [14.7 (11.7-18.3) $\mathrm{mmHg}](12,18)$.

Our findings need to be seen in the light of several limitations such as the lack of a comparison group, a singlecenter experience and the relatively small number of patients within our cohort. Although it is obvious that the overall significance of the present survival rates is therefore very limited, it seems remarkable that our survival rates are in line with data reported from larger trails such as PARTNER 2 Valve-in-Valve Registry (19) or CoreValve US Expanded Use Study (20) (survival rates at three years: $67.3 \%$ and $71.4 \%$, respectively).

In conclusion, ViV TAVI using balloon-expandable Edwards valves is safe and leads to acceptable functional results and may offer an effective, less invasive treatment for patients with failed FSB who are at high risk. However, early complications must be considered particularly during post-procedural hospital stay.

\section{Acknowledgments}

Funding: None.

\section{Footnote}

Conflicts of Interest: The authors have no conflicts of interest to declare.
Open Access Statement: This is an Open Access article distributed in accordance with the Creative Commons Attribution-NonCommercial-NoDerivs 4.0 International License (CC BY-NC-ND 4.0), which permits the noncommercial replication and distribution of the article with the strict proviso that no changes or edits are made and the original work is properly cited (including links to both the formal publication through the relevant DOI and the license). See: https://creativecommons.org/licenses/by-nc-nd/4.0/.

\section{References}

1. Durko AP, Osnabrugge RL, Van Mieghem NM, et al. Annual number of candidates for transcatheter aortic valve implantation per country: current estimates and future projections. Eur Heart J 2018;39:2635-42.

2. Duncan A, Moat N, Simonato M, et al. Outcomes Following Transcatheter Aortic Valve Replacement for Degenerative Stentless Versus Stented Bioprostheses. JACC Cardiovasc Interv 2019;12:1256-63.

3. Bleiziffer S, Simonato M, Webb JG, et al. Long-term outcomes after transcatheter aortic valve implantation in failed bioprosthetic valves. Eur Heart J 2020;41:2731-42.

4. Ejiofor JI, Yammine M, Harloff MT, et al. Reoperative Surgical Aortic Valve Replacement Versus Transcatheter Valve-in-Valve Replacement for Degenerated Bioprosthetic Aortic Valves. Ann Thorac Surg 2016;102:1452-8.

5. Sedeek AF, Greason KL, Sandhu GS, et al. Transcatheter Valve-in-Valve Vs Surgical Replacement of Failing Stented Aortic Biological Valves. Ann Thorac Surg 2019;108:424-30.

6. Sang SLW, Beute T, Heiser J, et al. Early Outcomes for Valve-in-valve Transcatheter Aortic Valve Replacement in Degenerative Freestyle Bioprostheses. Semin Thorac Cardiovasc Surg 2018;30:262-8.

7. Miller M, Snyder M, Horne BD, et al. Transcatheter Aortic Valve-in-Valve Replacement for Degenerated Stentless Bioprosthetic Aortic Valves: Results of a Multicenter Retrospective Analysis. JACC Cardiovasc Interv 2019;12:1217-26.

8. Bach DS, Kon ND. Long-term clinical outcomes 15 years after aortic valve replacement with the Freestyle stentless aortic bioprosthesis. Ann Thorac Surg 2014;97:544-51.

9. Ennker J, Meilwes M, Pons-Kuehnemann J, et al. Freestyle stentless bioprosthesis for aortic valve therapy: 17-year clinical results. Asian Cardiovasc Thorac Ann 2016;24:868-74.

10. Schneider AW, Putter H, Hazekamp MG, et al. Twenty- 
year experience with stentless biological aortic valve and root replacement: informing patients of risks and benefits. Eur J Cardiothorac Surg 2018;53:1272-8.

11. Reich H, Roselli EE. Defining the Limits of Valvein-Valve Transcatheter Aortic Valve Replacement for Degenerated Freestyle Bioprosthesis. Ann Thorac Surg 2020;110:1957-8.

12. Wai Sang SL, DeBruine N, Beute T, et al. Midterm Outcomes for Valve-in-Valve Transcatheter Aortic Valve Replacement in the Failed Freestyle Bioprosthesis. Ann Thorac Surg 2020;110:1951-7.

13. Kappetein AP, Head SJ, Généreux P, et al. Updated standardized endpoint definitions for transcatheter aortic valve implantation: the Valve Academic Research Consortium-2 consensus document. Eur Heart J 2012;33:2403-18.

14. Kasel AM, Cassese S, Leber AW, et al. Fluoroscopy-guided aortic root imaging for TAVR: "follow the right cusp" rule. JACC Cardiovasc Imaging 2013;6:274-5.

15. Choi CH, Cheng V, Malaver D, et al. A comparison of

Cite this article as: Burgdorf C, Vukadinovikj Momchilovska A, Remppis BA. Outcomes after transcatheter valve-in-valve implantation using a balloon-expandable Edwards Sapien valve in patients with degenerated Freestyle aortic bioprosthesis. Ann Cardiothorac Surg 2021;10(5):667-673. doi: 10.21037/acs-2021tviv-fs-43 valve-in-valve transcatheter aortic valve replacement in failed stentless versus stented surgical bioprosthetic aortic valves. Catheter Cardiovasc Interv 2019;93:1106-15.

16. Dvir D, Webb JG, Bleiziffer S, et al. Transcatheter aortic valve implantation in failed bioprosthetic surgical valves. JAMA 2014;312:162-70.

17. Bleiziffer S, Erlebach M, Simonato M, et al. Incidence, predictors and clinical outcomes of residual stenosis after aortic valve-in-valve. Heart 2018;104:828-34.

18. Huczek Z, Grodecki K, Scisło P, et al. Transcatheter aortic valve-in-valve implantation in failed stentless bioprostheses. J Interv Cardiol 2018;31:861-9.

19. Webb JG, Murdoch DJ, Alu MC, et al. 3-Year Outcomes After Valve-in-Valve Transcatheter Aortic Valve Replacement for Degenerated Bioprostheses: The PARTNER 2 Registry. J Am Coll Cardiol 2019;73:2647-55.

20. Dauerman HL, Deeb GM, O'Hair DP, et al. Durability and Clinical Outcomes of Transcatheter Aortic Valve Replacement for Failed Surgical Bioprostheses. Circ Cardiovasc Interv 2019;12:e008155. 